\title{
Turning mismanaged crisis into opportunity: Developing a municipal emergency communication plan for Puerto Rico
}

\author{
Mariely Valentin-Llopis \\ Barry University \\ Miami Shores, FL \\ USA
}

\begin{abstract}
Three years after Hurricane Maria, rural municipalities of Puerto Rico find themselves as vulnerable as before the category 4 storm dwindled the Island's resources. The town of Aguas Buenas is among the rural municipalities struggling to prepare for the next natural disaster. This pilot study provides a plan for activating the community with the purpose of forming the first community emergency management team (CEMT) in coordination with local officials. Through in-depth interviews with the people living in Aguas Buenas, the study presents a situation analysis followed by recommendations on how to train the community leaders and turn the crisis into an opportunity for collaborative engagement.
\end{abstract}

Keywords - community-centered, disaster, emergency communication plan, Hurricane Maria, Puerto Rico

SUGGESTED CITATION: Valentin-Llopis, M. (2020). Turning mismanaged crisis into opportunity: Developing a municipal emergency communication plan for Puerto Rico. Proceedings of the International Crisis and Risk Communication Conference, Volume 3 (pp. 29-32). Orlando FL: Nicholson School of Communication and Media. https://www.doi.org/10.30658/icrcc.2020.7

\section{INTRODUCTION}

This study aims at assessing the communication technologies available to people living in rural communities of the Island of Puerto Rico and developing a community-centered emergency communication plan (ECP) that is usable in times of crisis, namely natural disasters. The Government of Puerto Rico commissioned a $\$ 300,000$ study to George Washington University's (GWU) Milken Institute School of Public Health [1], which findings pointed at "very poor" communication practices between the central government and municipalities. Despite the Government of Puerto Rico's effort to understand what when wrong during the aftermath of Hurricane Maria, little has been put into practice after learning that an ECP was inexistent at the time this natural disaster left rural communities without power, water, and no form of communication for weeks.

Although the GWU report made recommendations focusing on the development of a robust ECP at the municipal level, people from rural vicinities such as Aguas Buenas have not heard of any such plan. This community is among the towns severely hit by the hurricane. Today, thousands of residents of Aguas Buenas are as vulnerable as they were back in 2017 due to the lack of preparedness at the state and municipal levels. Therefore, the need for an ECP pilot is critical in preparing for the next crisis, whether it be a natural or man-made disaster.

\section{THE PEOPLE OF AGUAS BUENAS}

The town of Aguas Buenas is located in the central mountain region of the Island of Puerto Rico, making telecommunications and transportation challenging for its approximately 28,000 residences. According to the United States Census Bureau [2], Aguas Buenas residents' median income is $\$ 17,255$. As of $2018,50 \%$ of the population is living in poverty and only $50 \%$ of the households have Internet broadband. The education level fairs better than other rural towns with over $65 \%$ of the population holding a high school diploma.

\section{LITERATURE REVIEW}

The government of Puerto Rico's management of Hurricane Maria turned a natural disaster crisis into an organizational crisis of international proportions. For instance, the impact of Hurricane Maria over the Island of Puerto Rico coupled with ISSN: 2576-9111

(C) 2020 Copyright is held by the owner/author(s).

Publication rights are licensed to ICRCC.

https://doi.org/10.30658/icrcr.2020.7 
the government's chaotic response produced a mass migration of hurricane refugees mainly to the East coast of the United States. Central Florida is one of the regions with the largest population of Hurricane Maria refugees. Therefore, the crisis in Puerto Rico is also creating vulnerabilities in Florida as public funding and urban planning must account for this new population and its needs.

For the purpose of this pilot study, it is important to make the distinction between the two types of crises mentioned above. Coombs' crises typology [3] is useful - "disasters are events that are sudden, seriously disrupting routines of systems," whereas organizational crisis refers to "perceived violation of salience stakeholder expectations that can create negative outcomes for stakeholders and/or the organization" (pp. 2-3).

Natural disaster preparedness through collaborative action is supported by scholars in the fields of public policy, technology, and business [4]. Furthermore, community action is as critical as the actions taken by the public and private sectors. Therefore, the study of international natural disasters through the perspectives of risk and crisis communication is evermore relevant [5]. The effects of severe weather conditions augmented by global warming have and will continue to strengthened; thus, the impact of hurricanes [6], earthquakes, wildfires, and droughts are of global concern [5]. In other words, we are all in this together whether we like or not.

Auerswald, Branscomb, La Porte, and Michel-Kerjan [4] study strategies to reduce public vulnerabilities caused by natural disasters (Hurricane Katrina) and terrorism (9/11). The scholars outlined seven findings to inform action, among the findings "acting with a clear recognition that interdependence is a multinational issue" (p. 491). Taken together, this brief review of the literature on the topic of crisis response to a disaster event supports the need for conceptualizing local crises as a global village problem. We can no longer ignore the issues or crises affecting geographically distant regions. The criterion for crisis preparedness based on geographical proximity or immediate threat is obsolete. All things are connected.

\section{METHOD}

This study followed a qualitative approach to explore the level of hurricane preparedness of the people of Aguas Buenas and the municipality's officials. The first phase of the exploration began with informal interviews of family and friends who live in Aguas Buenas. These informal interviews provided context for soliciting a formal interview with the Emergency Management Director of Aguas Buenas. The director and I spoke over the phone at length over issues relating to the current state of the town, the relationship between the municipality and the central government, and the need for resources to effectively respond to the next natural disaster (hurricane or earthquake, or both). In total, I logged over 4 hours of phone conversations with the director. Taken together, informal and formal interviews, support the development of a pilot ECP to: (a) assess current and available communication channels e.g. social media, telecommunications, and face to face meeting posts; (b) create an efficient channel of digital communication e.g. WhatsApp to connect residents with local agencies (city hall, urgent care clinics, schools) and local businesses (pharmacies, gas stations, convenient stores); and (c) promote the ECP among residents during the pre-crisis stage [3].

\section{SITUATION ANALYSIS}

In the aftermath of Hurricane Maria, an estimated 3,000 families (10\% of the population approximately) lost homes. The municipality's city hall building lost part of its roof and flooded. The generator powering the only school functioning as a shelter broke. Similarly, the generator powering the local emergency care clinic broke. The clinic was closed by its administrators due to structural damages to the emergency room. More than $95 \%$ of the town lost mobile communication due to fallen cellular towers. As of 2020, the municipality of Aguas Buenas lacks a comprehensive emergency and risk communication plan. The municipality's Emergency Management Office (EMO) has not received instructions, guidelines, or training from the state government on disaster response as recommended by the GWU report.

The EMO is functioning with a very small staff, six employees in total. Another aggravating factor is that the EMO is understaffed; therefore, the director goes out to the field responding to calls ranging from removal of wildlife to broken sidewalks. Director has no time to do his most important job, planning for a natural disaster, namely seismic activities and the upcoming hurricane season. Three years after Hurricane Maria, only one school was certified as a shelter facility. At the same time, the latest seismic activities have rendered the very same school premises as unsafe to operate. EMO is facing its own operational crisis due to limited capacity to respond to emergencies: motor vehicles shortage municipality do not own an ambulance vehicle, renting is expensive and increases response time, emergency response personnel is poorly trained, the municipality was awarded 14 power generators, only three are accounted for by the EMO, lack of emergency response supplies and equipment. As stated by the EMO director, the biggest hurdle continues to be the lack of a robust communication system. The new system should be satellite based due to Aguas Buenas geographical barriers and fragile infrastructure. The municipality has no functional Crisis Management Team (CMT) in place. The EMO director is beginning to assess and identify a community CMT by calling upon constituents with the willingness and expertise to serve as volunteer workers in the event of an emergency (medicine doctors, nurses, community leaders, social workers, and the like). 


\section{RECOMENDATIONS}

This pilot study's main recommendation is to train the community CMT adapting Boyd's OODA Loop [7, 8] to the assessment of risk and vulnerabilities during the hurricane pre-season running from January to April. As discussed in Coombs [3], the OODA Loop is about human reaction to stimuli- the time from when a person recognizes a stimulus to when they respond.

Figure 1- OODA LOOP - (Adapted from Boyd, 1987; Coomb, 2018, p.29)

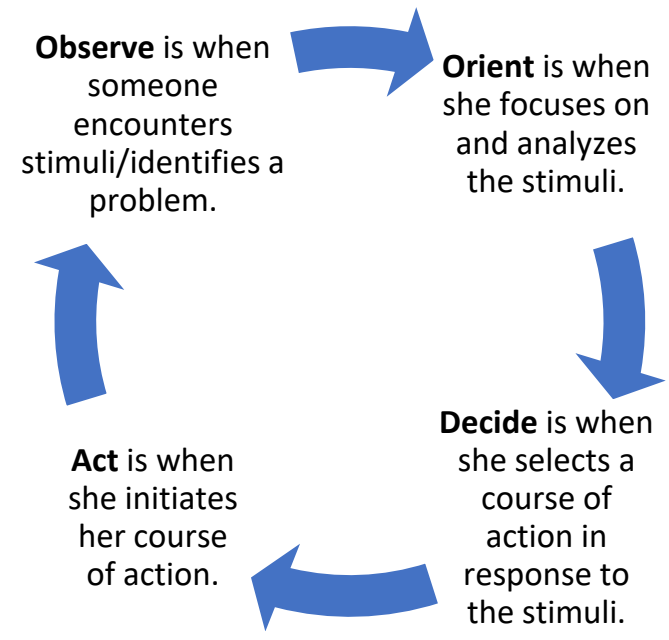

The nature of hurricanes, particularly, requires a system that activates the community team from the moment the storm systems begin to form. The following steps need to be clearly delineated, thus, the ODDA Loop serves as the starting point for community training aim at activating the community emergency management team (CEMT) as requested by the municipality's EMO. Community leaders should learn how to accurately monitor for risks and vulnerabilities, assessing resources, coordinating outreach initiatives for sensible populations, and leading the course of action during and after the disaster.

\section{DISCUSSION}

On the outset of this study, the focus is on community-centered action aim at reducing dependence on government response. The proposal is for municipalities to plan for collaboration with the central government. In the absence of the government's will for collaborative action, community preparedness becomes obligatory.

This study's emergency preparedness assessment of the municipality of Aguas Buenas reveals that in order to effectively implement an ECP, the needs of the region must be met. Among the critical needs, the followings were identified: (a) robust satellite-based communication system, (b) securing certified shelters across the municipality, (c) properly training and equipping the local EMO's staff, (d) engaging and training the community to effectively prepare and respond to the crisis. Evaluation of the pilot program consists of three main aspects (1) residents' feedback, (2) EMO and community CMT assessment of emergency response, (3) adjusting the ECP as necessary. After the pilot's evaluation phase, the goal is to roll out the ECP to adjacent rural municipalities.

\section{Author Biography}

Mariely Valentin-Llopis holds a doctoral degree in communication studies from Regent University. She is an Assistant Professor of Public Relations at Barry University, mvalentin-llopis@barry.edu

\section{REFERENCES}

[1] Santos-Burgoa, C., Goldman, A., Andrade, E., Barre, N., Colon-Ramos, U., Edberg, M, Garcia-Meza, A., Goldman, L., Roess, A., Sandberg, J. \& Zeger, S. (2018). Ascertainment of the Estimated Excess Mortality from Hurricane Maria in Puerto Rico. Washington, D.C.: George Washington University, Health Sciences Research Commons.

[2] United States Census Bureau. (2019, July). Quick facts: Aguas Buenas, municipio, Puerto Rico. https://www.census.gov/quickfacts/aguasbuenasmunicipiopuertorico

[3] Coombs, T. W. (2018). Ongoing crisis communication: Planning, managing, and responding (5th Edition). New York: Sage Publishing. 
[4] Auerswald, P. E., Branscomb, L. E., La Porte, T. M. \& Michel-Kerjan, E. O. Leadership. (2006). Who will act? Integrating public and private interests to make a safer world. In Auerswald, P. E. Seeds of Disaster, Roots of Response: How Private Action Can Reduce Public Vulnerability (pp. 483-501). Cambridge University Press.

[5] Schwarz, A., Seeger, M. W., \& Auer, C. (2016). The handbook of international crisis communication research. US: Wiley-Blackwell.

[6] Guha-Sapir, D., Hoyois, P., \& Below, R. (2014). Annual disaster statistical review 2013: The numbers and trends. Brussels: Centre for Research on the Epidemiology of Disasters (CRED).

[7] Boyd, J. R. (1987). Organic design for command and control. A discourse on winning and losing.

[8] Boyd, J. (2018). A Discourse on Winning and Losing (pp. 383-386, Rep.) (Hammond G., Ed.). Air University Press. 